AROUEOLOGÍA Y SOCIEDAD

№ 28 , 2014: $237-258$

ISSN: $0254-8062$

RECIBIDO: MARZO DE 2014

ACEPTADO: OCTUBRE DE 2014

\title{
SISTEMA DE TALLERES DE ARQUEOLOGÍA EN LA EDUCACION BÁSICA REGULAR
}

\author{
Ángelo ValderRama ZaVAla* \\ INSTITUTO CULTURAL RURICANCHO \\ arqueologiarecreativa@gmail.com
}

\section{RESUMEN}

Se parte de la idea que el curso de historia del Perú prehispánico en los niveles de primaria y secundaria de la Educación Básica Regular, por tener una gran cantidad de información, no solo debe de ser teórico, necesita ser complementado con visitas a los museos y los sitios arqueológicos, donde los estudiantes puedan entrar en contacto directo con aquellos elementos arqueológicos que les pueda permitir mediante su manipulación y observación poder describir, comparar, analizar y entender su funcionalidad, técnicas empleadas en su elaboración, grado de dificultad y el posible pensamiento que tuvieron los hombres o mujeres al momento de su elaboración. Este análisis permite poder realizar un aprendizaje más completo, que por medio de la experimentación se puede comprender mejor el proceso de desarrollo cultural de antiguos pueblos. Para poder hacerlo se necesita el conocimiento de algunos métodos y técnicas básicas de arqueología, sobre todo el experimental y por medio de ello se puede realizar reproducciones de distintos materiales arqueológicos con las mismas técnicas empleadas e iguales o similar materias primas que se usó al momento de su elaboración. De tal forma que el empleo de los conocimientos básicos en arqueología sirven como un recurso pedagógico en los colegios de los niveles de primaria y secundaria. Los objetivos son el de mejorar el nivel de enseñanza-aprendizaje en el curso de historia prehispánica del Perú, desarrollar identidad en los estudiantes por medio del conocimiento, respeto y valoración de elementos culturales propios de los antiguos peruanos, recuperar técnicas artesanales ancestrales en la elaboración de instrumentos y representaciones artísticas prehispánicas a punto de extinguirse, enseñar a valorar el uso de los recursos naturales o materia prima que encontramos en nuestro medio, crear gusto por la investigación en el campo de la historia y la arqueología, realizar reproducciones de instrumentos o manifestaciones de arte prehispánico por medio del uso de materia prima existente en el entorno. Los talleres son de industria lítica, arte rupestre, petroglifos, fibras vegetales, textilería y cerámica.

Palabras Clave: Arqueología, antropología, etnología, pedagogía, petroglifos, arte rupestre, prehispánico, unidad de aprendizaje, talleres de arqueología.

\section{Abstract}

The course of history Prehispanic Peru in primary and secondary levels of Basic Education , by having a large amount of information, must not only be theoretical, needs to be complemented with visits to museums

* Licenciado en Educación, UNMSM. Magister en Ciencias de la Educación con mención en Educación para la Creatividad en la Universidad de Ciencias Pedagógicas Enrique José Verona, Cuba. 
and archaeological sites where students may come into direct contact with those elements that they can afford archaeological using manipulation and observation to describe, compare, analyze and understand its functionality, techniques used in its preparation, degree of difficulty and the possible thought that men and women had to time of its preparation. This analysis allows us to conduct a more comprehensive learning, that through experimentation can better understand the process of cultural development of ancient peoples. To do so requires the knowledge of some basic methods and techniques of archeology, especially experimental and through this you can make reproductions of various archaeological materials with the same techniques and the same or a similar raw materials used at the time of processing. So that the use of basic knowledge in archeology serve as an educational resource in schools in the primary and secondary levels. The objectives are to improve the level of teaching-learning during Peru's pre-Hispanic history, students develop identity through knowledge, respect and appreciation of cultural elements of the ancient Peruvians, recover ancient craft techniques in the development of pre-Hispanic instruments and art performances to extinction, teach assessing the use of natural resources or raw materials found in our environment, create a taste for research in the field of history and archeology, make reproductions of instruments or demonstrations prehispanic art through the use of existing material in the environment. The workshops are lithic industry, rock art, petroglyphs, fibers, textiles and ceramics.

KEYwORDs: Archaeology, anthropology, ethnology, pedagogy, petroglyphs, rock art, pre-Columbian, learning unit, archeology workshops.

Hace miles de años, los antiguos peruanos descubrieron que podían elaborar herramientas y utensilios que mejorarían la calidad de sus vidas, observaron que la piedra, las fibras vegetales, el algodón, la arcilla y otros productos, puestos en sus manos y con el uso de su inteligencia podían convertirse en útiles puntas de lanzas, hachas, soguillas, redes, textiles, cerámica, etc. Con estas acciones transformaron los elementos encontrados en su entorno en riqueza y con ello pudieron ir dando forma a lo que constituiría sus primeros patrones culturales.

Todo el proceso de desarrollo cultural de estos primeros grupos humanos y posteriores pueblos y civilizaciones, hoy son estudiados ampliamente por diferentes disciplinas científicas, entre ellas la arqueología, antropología, etnología, etc. y sus aportes son muy valiosos para el entendimiento de estas sociedades.

Teniendo en cuenta lo anterior se debe considerar que la información de las disciplinas científica mencionadas anteriormente, puede ser utilizada en la enseñanza de la historia de una manera práctica, vivencial y creativa, convirtiéndose en un método de optimización de la calidad de la enseñanza y por consecuencia contribuir al mejoramiento del aprendizaje.

Las instituciones educativas pública y privadas del nivel básico, se convierten en un espacio necesario para la construcción de esos aprendizajes, y es allí, precisamente donde se debe desarrollar un conjunto de actividades o recursos pedagógicos que integren el conocimiento teórico con la propia experiencia del hacer y con esto se pueda construir su aprendizaje.

Se parte de la idea que en la educación básica regular, los programas curriculares en el área de historia, geografía y economía, por tener una gran variedad de información, no pueden ser solamente teórico, necesita ser complementado con visitas a museos, sitios arqueológicos y sobre todo entrar en contacto directo con los materiales culturales elaborados por los grupos humanos y civilizaciones que poblaron estas tierras, por medio de su análisis se comprenderá las técnicas empleadas para su elaboración, el grado de dificultad, la intencionalidad y sobre todo acercarnos al pensamiento de los hombres y mujeres anteriores al proceso de la conquista.

Los estudiantes necesitan construir sus propias respuestas, explicaciones, ideas y representaciones, necesitan conocer qué hicieron hombres y mujeres que los antecedieron, qué dificultades encontraron y cómo hicieron para superarlas, qué recursos obtuvieron de su medio ambiente para mejorar la calidad de sus vidas y qué creaciones culturales surgieron de dichas actividades y cómo fueron organizándose en torno a ellas. 
Para lograr esto, los maestros(as) de las instituciones educativas del nivel básico regular tienen la posibilidad de emplear como una vía diversos recursos pedagógicos, entendiéndose como ello a cualquier instrumento u objeto que pueda servir como recurso para que, mediante su manipulación, observación o lectura se ofrezcan oportunidades para aprender algo, o bien con su uso se intervenga en el desarrollo de alguna función de la enseñanza. ${ }^{1}$

La aplicación de algunos conocimientos en arqueología se convierte en un excelente recurso pedagógico en el nivel de secundaria en la educación básica regular. Es de entender que la arqueología más allá de ser una ciencia que estudia al hombre antiguo, su medio y sus obras; no empieza ni culmina con una excavación arqueológica, la descripción y el análisis de los materiales descubiertos; se ha visto en los últimos años su gradual apertura a temas, aspectos y contextos relacionados con la educación patrimonial por medio de la transmisión de los conocimientos arqueológicos en la enseñanza -aprendizaje y en el desarrollo de la creatividad. No obstante, los maestros aun cuando ven en la arqueología una herramienta didáctica muy útil para desarrollar ciertas competencias de aprendizaje en el aula, la gran mayoría tienen un conocimiento superficial de las teorías, metodologías y técnicas de la arqueología moderna, de forma que el resultado de su uso en el aula habitualmente es poco representativo de su potencial y por supuesto en ese sentido no representa una herramienta pedagógica. En tal situación existe una brecha comunicativa significativa entre los investigadores y los maestros, donde se puede conectar con un nivel de transmisión de información de las investigaciones, metodologías y técnicas en arqueología que sirvan para que los maestros con sus conocimientos pedagógicos lo puedan adecuar a su contexto educativo.

Existe un escaso tratamiento de la arqueología como una forma de desarrollar aprendizajes, sobre todo en el primer grado del nivel de secundaria en la educación básica regular, donde existen temas de historia prehispánica; los conocimientos generalmente están limitados a definiciones y descripciones de acuerdo a las capacidades trabajadas sobre los temas en las clases o de explicaciones simples o complejas expuestas por guías cuando se realizan visitas de estudio programadas a museos o sitios arqueológicos. En los museos los estudiantes no pueden entrar en contacto directo con los materiales arqueológicos, no se pude manipular para realizar una interpretación de las técnicas empleadas, la utilidad y el nivel de dificultad por ser un material muy delicado y de mucho valor histórico o arqueológico, a esto se le suma que lamentablemente la literatura científica sobre el tema de arqueología y su relación con la educación en el ámbito metodológico es muy escaso en nuestro país.

Se sabe que en la totalidad de los colegios para el estudio de la química, biología, anatomía y la física, se cuentan con sus respectivos talleres o laboratorios de ciencias, donde los estudiantes complementan la parte teórica con la manipulación y la experimentación científica mejorando su nivel de aprendizaje, por lo tanto si otras asignaturas cuentan con un laboratorio o talleres donde se tiene la oportunidad de aprender experimentando, entonces ¿Por qué no dar la existencia de un sistema de talleres de arqueología donde los estudiantes tengan la misma oportunidad de aprender a través de la interpretación, el análisis, la experimentación y la elaboración?

Entonces se puede entender al sistema de talleres de arqueología en la educación básica regular como una forma organizada de desarrollar actividades pedagógicas interconectadas y que constituyen un conjunto de partes o elementos organizados y relacionados que interactúan entre sí para lograr un objetivo que por medio de sesiones de clase los estudiantes desarrollan su propio aprendizaje por medio de conocimientos básicos de arqueología. Por otro lado los talleres ofrecen una metodología nueva de trabajo no sólo al docente de ciencias, sino a los profesores de otras áreas del conocimiento. Según Alberto Jiménez Vélez, los talleres son espacios en el cual se generan saberes, interacciones, usos y formas que constituyen la expresión de un proceso lógico. ${ }^{2}$

1 Gimeno (2001: 55).

2 Jiménez (1990: 194). 
En los talleres de arqueología los estudiantes puedan desarrollar actividades complementarias al curso de historia, donde puedan entender todo el proceso de elaboración de diferentes elementos que pueden fácilmente encontrar en su entorno y con el empleo de antiguas técnicas prehispánicas pueden realizar creaciones que le ayuden a comprender el pensamiento y las intenciones dentro de sus contextos sociales de los antiguos pobladores del Perú.

Los talleres de arqueología transmiten una idea de historia que no sólo se ve, sino que también se puede tocar, recrear y sentir. Apoyándose en conceptos didácticos y el desarrollo del interés hacia el Patrimonio, convirtiendo al estudiante en el actor de su propio aprendizaje.

En setiembre de 1986, en el primer Congreso Mundial de Arqueología (World Archaeological Congress), celebrado en Southampton, Inglaterra, la arqueología sufre un cambio; por un parte los académicos reunidos el congreso mundial dedicados a las investigaciones arqueológicas, se dieron cuenta de la importancia que tiene la difusión y educación de ésta, incluyéndolo como una recomendación en las conclusiones finales del congreso mundial y por otro parte los educadores comenzaron a involucrarse con el tema y a incluir, de forma básica y experimental, a la arqueología en sus clases. ${ }^{3}$

Estos cambios que surgen en el enfoque de la difusión y enseñanza del conocimiento arqueológico, motivados por incluir al público y en especial a estudiantes de educación básica, abren un campo en la disciplina, cuyos objetivos se centran en la preservación de patrimonio arqueológico y la toma de conciencia sobre el pasado del hombre. ${ }^{4}$

De esta forma, en varios países del mundo, como Inglaterra, Estados Unidos, Italia, España o India, la arqueología comienza a ser integrada dentro de los salones de clase, ya sea como forma de divulgar el trabajo arqueológico y la importancia que éste tiene para la construcción del pasado. ${ }^{5}$

En América Latina, incluyendo al Perú, su práctica es novedosa y esporádica, relacionada casi siempre con cursos o talleres vacacionales para escolares desarrollados por especialistas o investigadores en arqueología, realizados en museos o en algunos sitios arqueológicos.

En el actual sistema educativo, el diseño curricular nacional fundamenta en el área de historia, geografía y economía la necesidad de la construcción de una identidad social y cultural relacionado con un conjunto de aprendizajes por medio de los cuales la persona construye su concepción del tiempo y el espacio a partir del análisis y reflexión sobre su propia realidad, interrelacionando el presente, pasado y futuro. Este aspecto es importante puesto que resalta la importancia del desarrollo de una identidad que está en proceso de construcción y el empleo de diversas actividades pedagógicas que se pueden utilizar para logra dicho fin; incluyendo los conocimientos arqueológicos y considerando que la característica del currículo educativo es diversificable, abierto y flexible con el fin de responder a las características de los estudiantes y del entorno.

Por otro lado los texto que proporciona el Ministerio de Educación en el nivel secundaria en las instituciones educativas públicas de educación básica regular por una conocida editorial en el área de historia, geografía y economía en el primer grado de educación secundaria, contienen unidades que definen el mundo prehispánico y prehistórico, aunque se sobre entiende el papel de la arqueología en el texto para construir el conocimiento histórico de ésos periodos, no se profundiza más allá. Tampoco se dedican espacios para aclarar su relación con la historia y demás disciplinas. Esto provoca que los estudiantes no tengan claro lo que es la arqueología, y su importancia.

A diferencia de otros países, en donde la arqueología se ha integrado a la educación formal; en el Perú existe poco intento. Si bien es cierto que actualmente dentro de las Orientaciones para el Trabajo Pedagógico (OTP- 2010) en el capítulo III que corresponde a las orientaciones para la enseñanza y el

3 Bereskin (2000: 35).

4 Davis (2000: 47).

5 Henson (2001: 126). 
aprendizaje del área de historia, geografía y economía se plantea una estrategia relacionada al desarrollo de proyectos de investigación donde se recomienda que el estudiante entre en contacto directo con el trabajo de especialistas relacionados a la historia, geografía, arqueología, antropología, etc. En ningún momento se orienta sobre la importancia de la arqueología para generar conocimientos y aprendizaje.

En conclusión se pude determinar que existe una necesidad de incorporar algunos conocimientos básicos de arqueología en la enseñanza aprendizaje de la historia del Perú prehispánico en el área de historia, geografía y economía en el primer grado de educación secundaria básica regular.

Para el desarrollo de los talleres se debe tener en cuenta que el área dispone de tres horas pedagógicas (45 minutos cada hora) a la semana. Cada taller es trabajado en dos sesiones divididas de la siguiente manera:

\section{Primera sesión}

(45 minutos) en una hora pedagógica se desarrolla la parte metodológica.

\subsection{Captación de pre conceptos}

Son los conocimientos que el estudiante ya trae consigo, se adquiere mediante el planteamiento de preguntas: ¿Por qué? causa / motivo, ¿Quiénes? Personajes, ¿Dónde? lugar, ¿Cuándo? tiempo, ¿Cómo? técnica, ¿Para qué? consecuencia. Para ello se pueden mostrar imágenes o réplicas arqueológicas.

\subsection{Uso de fuentes históricas}

Comprenden todos los documentos u objetos que nos transmiten una información significativa.

- Observación y manipulación de materiales didácticos. (Fuentes materiales)

Se muestra a los estudiantes réplicas arqueológicas o diversos materiales didácticos relacionados al tema del taller. Los estudiantes analizan el material.

- Formulación de la hipótesis. Los estudiantes luego del análisis de las fuentes materiales proponen diversas hipótesis sobre su elaboración (técnicas empleadas, intencionalidad, grado de dificultad, tipo de pensamiento que tuvieron al momento de elaborarlo)

- Lectura de documentos: (Fuentes escritas). Consiste en la búsqueda y lectura de documentación o información sobre las técnicas empleadas para la elaboración del material. Sirve para comprobar o descartar las hipótesis planteadas por los estudiantes.

\section{Segunda sesión}

(90 minutos) en dos horas pedagógicas se desarrolla la parte correspondiente a la interpretación o experimentación, esta consiste en el desarrollo de cada taller.

Es el procedimiento del taller, se aplica lo aprendido por el estudiante. Sirve para comprobar si el nuevo saber ha sido comprendido y adquirido sobre las diferentes técnicas en la elaboración.

\section{Plan de Acción de los TAlleres de ARQueología}

Para ser desarrollado en la secuencia metología de la interpretación) (para ser desarrollado en la segunda sección de 90 minutos).

\section{TALLER 1: INDUSTRIA LÍTICA}

\subsection{DESCRIPCIÓN}

Consiste en reproducir diversas herramientas líticas desde las primeras piedras talladas por una cara, hasta los complejos como los bifaciales, basadas en ciertos conocimientos de las leyes de fractura de 
rocas y el empleo de técnicas adquiridas con la transmisión de los conocimientos de generación en generación, logrando crear diversos instrumentos de cacería, defensa, guerra y para diversos usos cotidianos. De acuerdo a ello surge una clasificación.

De acuerdo a la época, tiempo o zona la terminología en cuanto a la clasificación varía, básicamente podemos encontrar algunas clasificaciones que van desde la más antiguas con tres millones de años correspondientes a la primera fase Olduvaienses pertenecientes al Paleolítico Inferior, eran herramientas talladas en roca de manera muy tosca y simple, generalmente en una sola cara (unifaciales) que servían para abrir la piel de los animales.

La segunda fase Achelense se da con la aparición del Homo Erectus y lo más característico en esta fase es la aparición de la herramienta multiuso del paleolítico «El Bifacial» una roca tallada en forma de almendra o lagrima, esta roca tiene filos laterales y puede ser usado para cortar, como cuchillo, hacha, perforador y para picar.

La tercera fase es la Musteriense, esta se da con la aparición del Neanderthal en el paleolítico medio, la forma de tallar es trabajar con un nódulo de roca al cual se le trabaja con golpes extrayendo un núcleo y con ello laborar distintas herramientas muy elaboradas como punzones, cuchillos denticulados, raederas y percutores.

La cuarta fase corresponde a la Auriñaciense y su uso es del Cromagnon. Los núcleos son obtenidos de forma alargada de donde extraen hojas largas, delgadas y paralelas, luego se retoca con golpes suaves con un percutor blando obteniendo un buen filo y belleza, las rocas destinadas para lanzas presentan un pedúnculo o rabo. En esta fase también se comenzó a utilizar huesos y asta de venado.

\subsection{OBJETIVO}

Elaborar herramientas líticas con el empleo de rocas que se encuentran en el entorno y el uso de técnicas muy antiguas.

\subsection{TIEMPO DE DURACIÓN}

90 minutos.

\subsection{MATERIALES}

Percutor, compresores, alisadores, roca silex, roca obsidiana, cuarcita, andesita o granodiorita.

\subsection{TÉCNICAS}

Dos son las técnicas empleadas: percusión o tallado y la presión.

Teniendo en cuenta esto se puede usar piedras para dichos propósitos, estas no deben ser muy duras para su posterior fraccionamiento, existen dos métodos muy conocidos, una se basa en la percusión : Con un martillo de piedra ( piedra dura de canto rodado) o de hueso (preferentemente de asta de un animal) se da un golpe a la superficie de una piedra de cantera para arrancarle astillas, tallando las dos caras y los bordes con esto se pueden confeccionar tajadores, hachas de mano, raspadores, buriles, etc.

La otra técnica, innovación muy posterior, es el método de presión, en que se desprende una hoja con instrumento aguzado, lo que da una astilla más fina y un borde más afilado con ello se podían confeccionar puntas de lanza, navajas, utensilios dentados, perforadores, etc. 


\subsection{PROCEDIMIENTOS}

- INICIO: Se inicia mostrando imágenes y réplicas de herramientas líticas, se explica la función que tenían y las técnicas empleadas en su elaboración.

\section{- PROCESO}

PRIMERO. Se debe tener en cuenta el uso de todos los materiales necesario y sobre todo de la seguridad industrial para la elaboración, es por ello que se debe tener en cuenta el uso de gafas de protección industrial, un mandil de cuero y unos guantes de construcción.

SEGUNDO: La elaboración del tallado es recomendable realizarlo en campo abierto, es decir fuera de las aulas, pudiendo ser el patio o una zona de campo.

TERCERO: Empezar el tallado desde las formas más simples y para ello es conveniente trabajar con la técnica de la percusión o tallado. Con un martillo de piedra (canto rodado) el estudiante «artesano» da un golpe seco justo detrás del núcleo de la piedra, el impacto hace saltar una astilla debajo, dejando una honda huella.

De un guijarro redondeado sale un tajador. Esta vista muestra como se desprenden hojas con un martillo de piedra, luego se gira la piedra y se repite el procedimiento al saltar otra hoja, el utensilio adquiere un borde corto, irregular y afilado (Fig. 1).

CUARTO: La técnica final es la de presión. Con un martillo de hueso o madera se golpean los bordes del utensilio para dar el acabado final haciendo saltar astillas con un instrumento puntiagudo de madera o hueso. Se hace saltar una hoja plana de la cara inferior presionando suave y con movimientos hacia abajo dándole un filo o borde muy agudo (Fig. 2).

- EVALUACIÓN: Se evalúa el proceso y el producto final, mostrando el empleo y conocimiento de la técnica al momento de elaborarlos (Fig. 3).

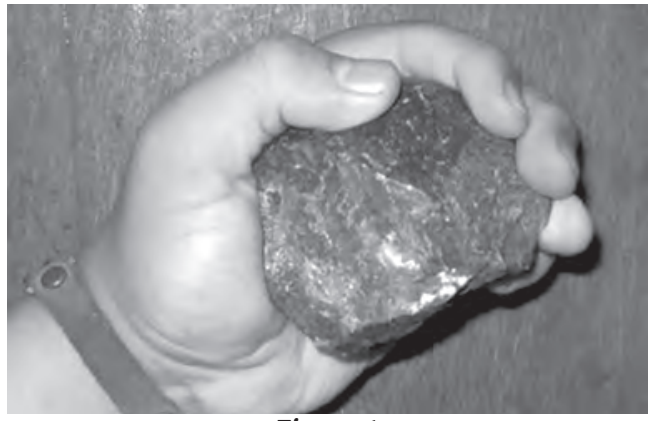

Figura 1

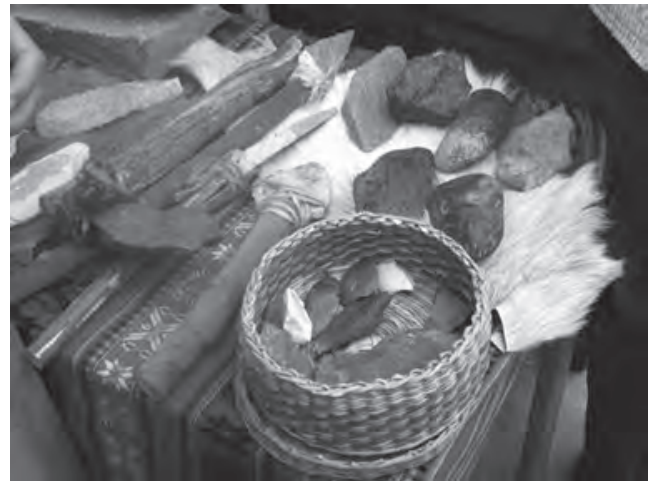

Figura 2

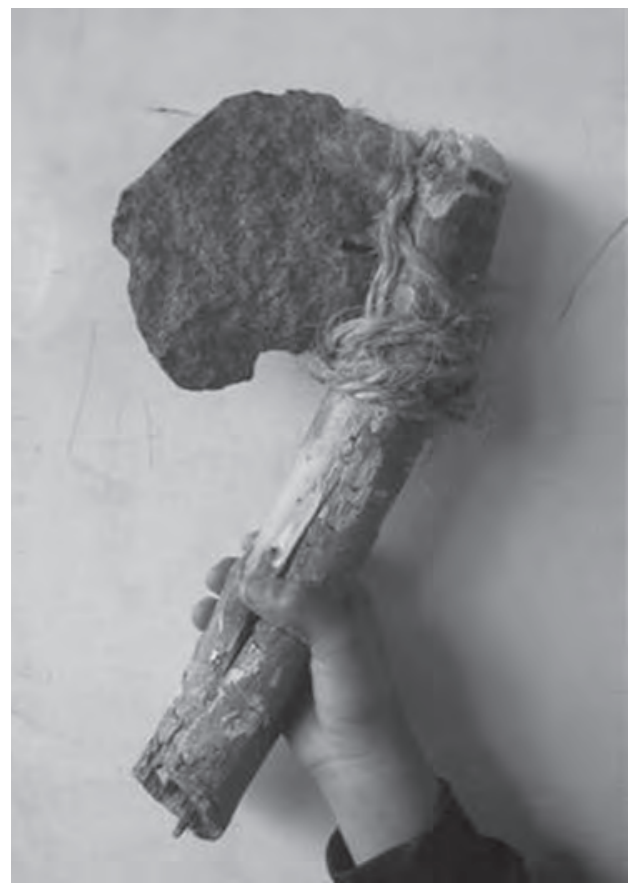

Figura 3 


\section{TAller 2: Arte Rupestre (Pictografías)}

\subsection{DESCRIPCIÓN}

El arte rupestre es obra de los diferentes grupos culturales del mundo antiguo y del Perú prehispánico. Estos grupos reprodujeron sus figuras humanas y símbolos mágico religioso en cuevas, paredes rocosas, aleros y abrigos naturales. El arte rupestre incluye también a los geoglifos y petroglifos que se encuentran en abundancia por todo nuestro territorio peruano. Las pinturas rupestres fueron usadas por un largo periodo de tiempo, desde el Periodo Lítico hasta el Horizonte Tardío y algunos se diseñaron aun a comienzos de la época colonial. Sobre el significado de los símbolos y figuras es aún desconocido, la razón principal es la carencia de crónicas o registros semejantes con los que podamos contrastar y comparar, pero en muchos de ellos aparecen animales y seres que son semejantes a las figuras de las cerámicas de culturas posteriores, lo cual posiblemente nos indique que cumplían un rol mágico religioso, pero el significado exacto hasta ahora constituye para los arqueólogos un problema por resolver.

Esta modalidad de arte rupestre se caracteriza por utilizar en su preparación sustancias minerales (oxido de hierro, manganeso, cinabrio, carbón, arcillas), animales (sangre, huevos, grasas) o pigmentos que van desde el negro hasta el blanco, pasando por una amplia gama de rojos ocre, naranjas y amarillos.

En muchas pictografías se observa diversos tonos de rojo y otros colores, lo que dice que los pintores sabían hacer las diferentes mezclas de los materiales para obtenerlos.

Además de pintar con las manos, el hombre primitivo hacía uso de instrumentos como por ejemplo:

- Pinceles de pelo animal para conseguir trazos finos o pintar grandes superficies.

- Ramas quemadas, bolas de arcillas y resina.

- Cañas huecas para soplar el pigmento a modo de aerógrafo.

\subsection{OBJETIVO}

Elaborar distintas formas de pictografías por medio de imágenes, símbolos e iconografía, empleando materiales y distintas técnicas muy antiguas.

\subsection{TIEMPO DE DURACIÓN}

90 minutos.

\subsection{MATERIALES}

Una roca mediana, tosca, rugosa o lisa de jardín, plana por uno de sus lados (debe estar limpia), tierras de color (rojizo, amarillo y negro), recipientes para preparar los colores, clara de huevo, dos ramitas de arbolito de $0,5 \mathrm{~cm}$ de diámetro por $15020 \mathrm{~cm}$ de largo aproximadamente (para elaborar nuestro pincel natural) una pluma pequeña o mediana de cualquier color, dos cartulinas negras tamaño A4, pincel delgado, tempera roja y amarilla, papel higiénico (para limpiarse las manos), periódicos pasados, una bolsita plástica para desperdicios, imágenes de pinturas rupestres.

\subsection{TÉCNICAS}

Explicación de las técnicas.

- La dactilografía. Es el empleo de los dedos para realizar trazos o puntos. Con ello se consigue trazos gruesos y delineados, pudiendo representarse puntos, rectas, diagonales, círculos y símbolos.

- La impronta manual. Consiste en emplear la palma de la mano cubierto totalmente de pigmento y se coloca sobre la roca a manera de sellos. Es una técnica muy antigua que servía para poder representar símbolos o marcar algún territorio o demostrar presencia. 
- Aplicación con instrumento. Para ello se utiliza una pluma, ramita con un extremo escobillado o un hisopo de algodón o piel de animal, los trazos salen más finos. Servían para realizar trazos muy bien delineados y muy finos, los utilizaban para realizar retoques o aplicaciones a los trazos gruesos mejorando su presentación.

- Pintura en negativo o aereografiado, Con la ayuda de un canutillo o embebiendo el pigmento y manteniéndolo en la boca, se procede a expulsar el pigmento en forma de fumigado a una distancia aproximada de $30 \mathrm{~cm}$. sobre la mano colocado en forma palmeada sobre la roca, luego se retira la mano quedando la imagen en negativo.

El uso de aglutinantes en el pigmento es importante puesto que ayuda a que el color pueda fijarse sobre la roca más tiempo y soportar las inclemencias del tiempo, humedad, erosión, etc.

\subsection{PROCEDIMIENTOS}

- INICIO: En esta parte se da a conocer la teoría y se muestra con apoyo de imágenes diversas formas de representaciones de pictografías en el Perú y el mundo, se analiza la simbología y las intensiones o necesidades que tenían los antiguos grupos humanos que realizaron estas pictografías.

\section{- PROCESO}

PRIMERO: Se tiene en cuenta los materiales a ser usados por los estudiantes.

SEGUNDO: En esta parte el trabajo es de análisis de iconografías. Los estudiantes en una cartulina preferentemente negra y de tamaño A4, representaran imágenes iconográficas creadas por ellos mismos utilizando los colores característicos como el rojo, amarillo, blanco y crema, luego en la parte inferior de su pintura redactarán la explicación de su iconografía, esta debe estar relacionado con algún proceso de forma de sobrevivencia, cosmovisión o entendimiento del mundo de aquellos hombres y mujeres que vivieron en periodos muy antiguos en el Perú. Las técnicas empleadas en la cartulina serán la dactilografía, la impronta manual o la utilización de un instrumento (Fig. 4).

TERCERO: Teniendo la experiencia de trabajar en cartulina representando sus propias iconografía de manera creativa, ahora realizaran representaciones de pictografías en roca, para ello deben contar con un fragmento de roca limpia y de aproximadamente unos $20 \mathrm{~cm}$ a $30 \mathrm{~cm}$ de largo, en ella representarán imágenes de pictografía empleando cualquiera de las técnicas aprendidas. Recordar que la preparación del pigmento debe ser con tierra de color puesto que el conseguir óxidos es muy complicado y puede ser tóxico, de manera que el empleo de arcillas, tierras de color son lo más cercano a la materia prima original, este pigmento debe ser combinado en un recipiente con un poco de agua y un aglutinante para que pueda fijarse en la roca al momento de ser pintado, originalmente se usó el mucílago extraído de plantas, en este caso se empleará un poco de clara de huevo que se juntará al pigmento y luego debe ser mezclado hasta obtener una consistencia espesa par ser aplicado con un instrumento, dedos o palma de la mano (Fig. 5).

- EVAlUACión: Se evalúa el proceso y el producto final, mostrando el empleo y conocimiento de la técnica y la creatividad al momento de elaborarlos. Se evalúa la iconografía y su respectiva explicación, la roca y la técnica empleada (Fig. 6).

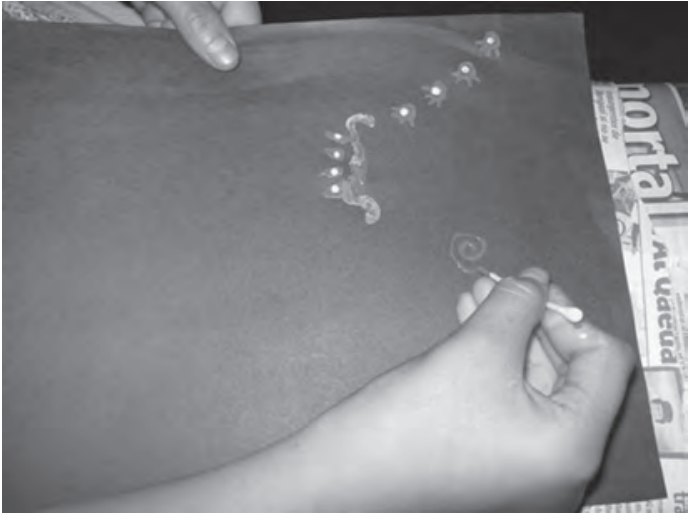

Figura 4 


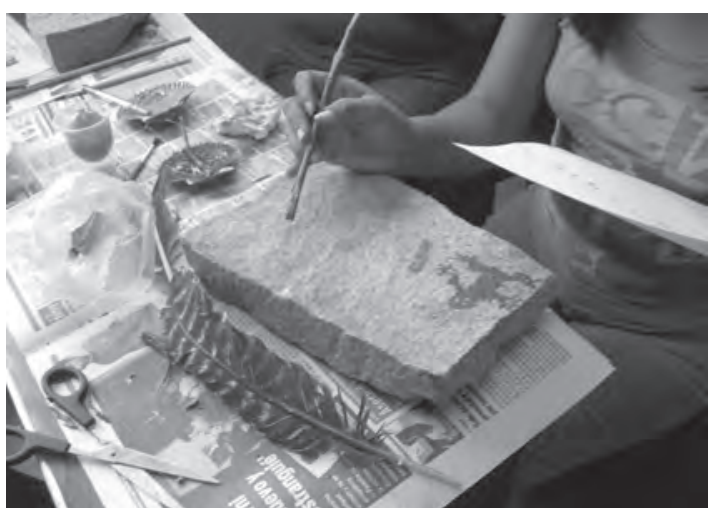

Figura 5

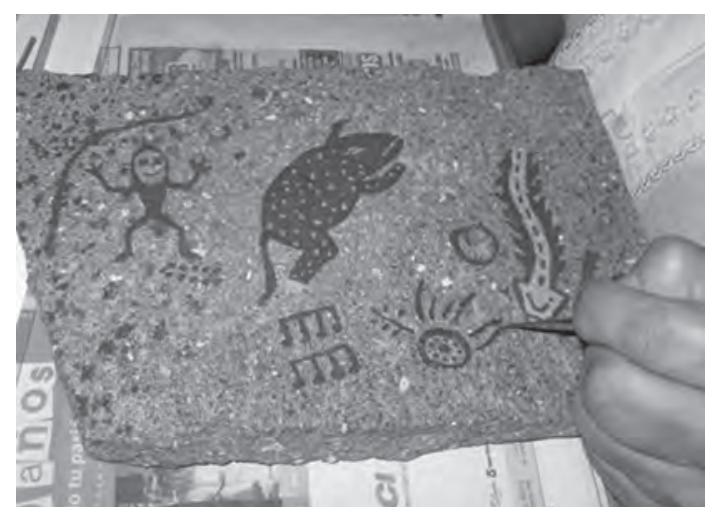

Figura 6

\section{TAller 3: ARTe RUPESTRe (elaboración De PETROGlifos)}

\subsection{DESCRIPCIÓN}

Es una o varias imágenes que han sido grabados en las superficies de las rocas y que fueron decoradas con diferentes imágenes de figuras humanas, animales, plantas y seres míticos relacionados posiblemente con el culto solar, lunar y culto al agua que siempre fue escasa en el Perú prehispánica. Los petroglifos fueron usados desde el Periodo Lítico hasta el Horizonte Tardío, lo cual significa que no siempre fueron usados por los grupos que carecían de cerámica o tecnología avanzada comparada con los grupos más remotos.

Estas manifestaciones fueron elaboradas al sustraer material de la superficie rocosa con instrumentos de una dureza superior. Para lograrlo, el antiguo ejecutor pudo utilizar punteros de piedra $u$ otros elementos elaborados específicamente para tal fin, pero hasta ahora en el Perú no se ha podido hallar herramientas de este tipo que se puedan asociar con algún sitio rupestre.

Las imágenes grabadas transmiten ideas y significados a la mente sin necesidad de usar palabras, sonidos $u$ otras formas de lenguaje. A este método primitivo de comunicación se le llama escritura con imágenes y a partir de él se ha formado la base de los caracteres que se usan hov en China. Japón y otros países. Los indios norteamericanos y la civilización incaica no tenían lenguaje escrito. La manera que tenían de mantener vivas sus tradiciones e historia era pasándolas de padres a hijos en forma de relatos orales.

Los diseños de los grabados varían dependiendo lo que querían transmitir, su elaboración estaría asociada al culto a sus divinidades, al agua, señales en el camino, etc.

Gracias a los petroglifos, los hombres y mujeres antiguos podían comunicarse y dejar registros sobre las piedras, por lo que se considera que esta técnica es un antecedente lejano de la escritura (Fig. 7).

\subsection{OBJETIVO}

Elaborar petroglifos de manera creativa con el empleo de rocas que se encuentran en nuestro entorno y empleando las mismas técnicas de elaboración.

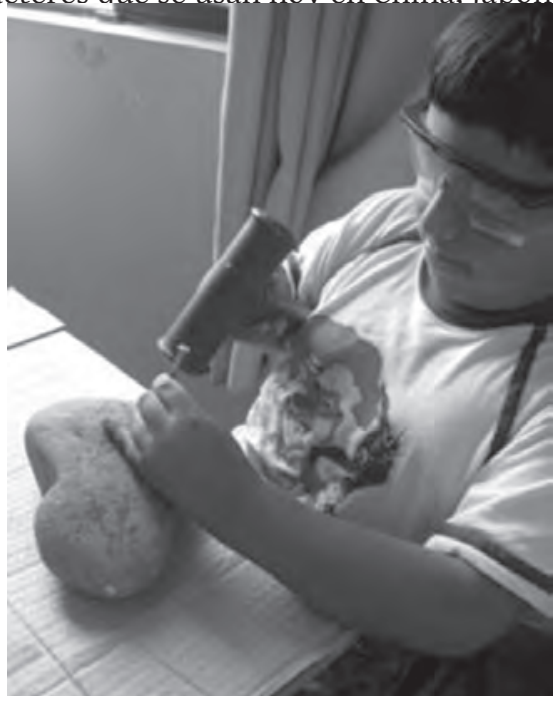

Figura 7 


\subsection{TIEMPO DE DURACIÓN}

90 minutos.

\subsection{MATERIALES}

Una roca de canto rodado, mediana, limpia, aplanada y porosa (fijarse que no sea de superficie lisa o dura),un lápiz carboncillo, un clavo de cemento de 4 pulgadas (cabeza normal, no en forma de L), una piedra percutor redonda u ovalada, ajustable a la palma de la mano, pedazos de cartón grueso (de leche, aceite, etc.) de aproximadamente 20 x $30 \mathrm{~cm}$ imágenes de petroglifos.

\subsection{TÉCNICAS}

Explicación de las técnicas.

- PERCUSIÓN: Consiste en picar la roca con otra roca o metal más duro siguiendo un trazo que define una imagen o símbolo, mediante el golpeteo constante con otro instrumento auxiliar, a la manera del cincel y el martillo.

- PICOTEADO: Consiste en picar la roca a manera de pequeños o medianos puntos generalmente dentro de los límites de un grabado previo dándole un efecto de relleno o textura.

- RAYADO: Consiste en rayar la roca con un instrumento de mayor dureza y lograr con ello un trazo generalmente no muy profundo, evitando en todo momento el contacto de la percusión. También fue utilizado para retocar trazos de percusión.

- DESCASCARADO: Consiste en retirar capas superficiales de la roca con la ayuda de un instrumento metálico, dejando el efecto de descascarado. Esta aplicación generalmente se aplica dentro de los límites de un grabado previo para dar un efecto de relleno.

- ABRASIÓN: Consiste en frotar la superficie de la roca con un instrumento de piedra ovalada produciendo un desgaste y por lo tanto abrasión, dejando una zona cóncava. Finalmente se le pule con la ayuda de arena y agua.

\subsection{PROCEDIMIENTOS}

- INICIO: Se inicia mostrando imágenes de petroglifos muy conocidos como los de Checta, luego se describe y se busca entender el mensaje que podrían transmitir, se establecen definiciones e importancia y técnicas para su elaboración.

- PROCESO

PRIMERO: los estudiantes elaboran de forma creativa sus propias imágenes, diseños e iconografías que luego son dibujadas sobre la roca.

SEGUNDO: con el lápiz carbón se dibuja la imagen previamente diseñada sobre la roca de canto rodado de aproximadamente entre $20 \mathrm{~cm}$ a $30 \mathrm{~cm}$.

TERCERO: La roca es colocada sobre una superficie firme y apoyada sobre cartones gruesos para amortiguar los golpes al momento de realizar las diversas técnicas.

CUARTO: La roca estabilizada en una posición definida es sometida a las técnicas, con un instrumento de mayor dureza (Cincel) que en este caso es un clavo de cemento de cuatro pulgadas (tamaño adecuado a la palma de la mano) se procede a golpear y retirar fragmentos de la capa superficial de la roca pudiendo ser por medio del rayado o la percusión con una roca o martillo. (Fig. 8).

- EVALUACIÓN: Se evalúa el proceso y el producto final, mostrando el empleo y conocimiento de la técnica y la creatividad al momento de elaborarlos. Se evalúa la iconografía del petroglifo, su respectiva explicación y la técnica empleada (Fig. 9). 


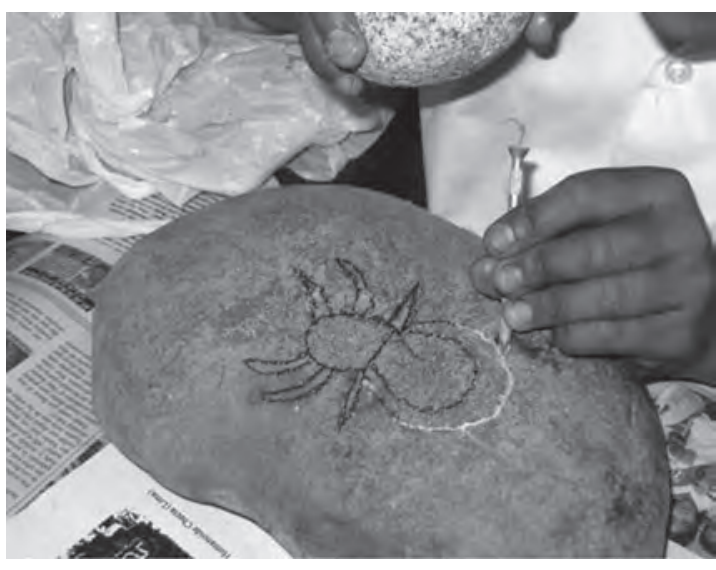

Figura 8

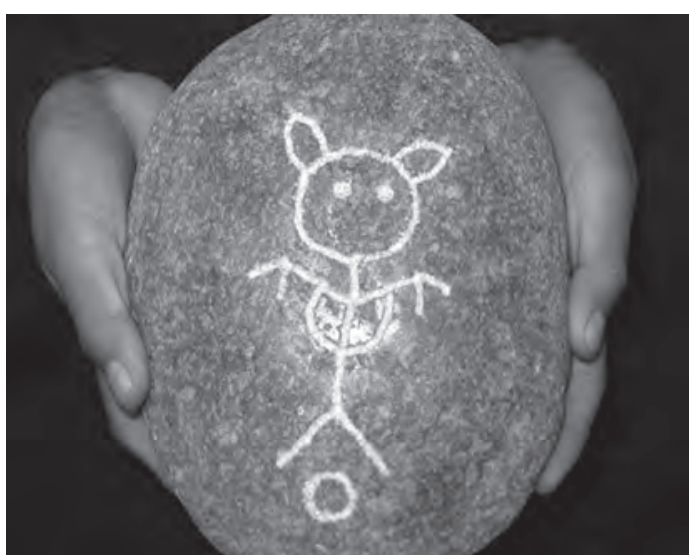

Figura 9

\section{Taller 4: Fibras vegetales (elaboración de collares del Precerámico)}

\subsection{DESCRIPCIÓN}

La práctica de hilar y tejer es una de las actividades más antiguas de la humanidad. Desde el paleolítico el hombre utilizó tejidos más o menos rudimentarios para protegerse de las inclemencias del tiempo. Empleo anchas fibras vegetales sin hilar que cortaba en tiras, secaba y después entretejía hasta formar una especies de tela. A este conocimiento se le unía el hecho de adornarse y para ello empleaba elementos que podía utilizar y conocer. La necesidad de usar adornos, entre ellos collares y pulseras, esto era una necesidad que no necesariamente estaba relacionada con la simple vanidad, en muchos casos estaría directamente relacionado con algún tipo de status social, identificación o un acercamiento con sus creencias o divinidades.

En todo caso la necesidad estaba y debía de cubrirla, es por ello que utilizó fibras vegetales que con la suma de conocimientos que ya tenía acumulado pudo plasmarlo en bellas representaciones artísticas; cordeles de fibras vegetales bellamente trenzadas y pintadas con oxidos y rematados con pendientes sacados de su entorno natural y contexto geográfico como moluscos, choros, semillas, huesos o maderas talladas. El hombre y la mujer del periodo lítico o precerámico cumplía con vivir de acorde a su desarrollo y conformación cultural, el adornarse era parte de ello y más valor aún si esos objetos estaban relacionados con sus logros en alimentación, producción y satisfacción.

\subsection{OBJETIVO}

Elaborar collares del precerámico de forma creativa con el empleo de fibras vegetales que se encuentran en nuestro entorno y empleando las mismas técnicas con las cuales se confeccionaron.

\subsection{TIEMPO DE DURACIÓN}

90 minutos.

\subsection{MATERIALES}

Una hoja o penca de maguey (tamaño grande), periódicos pasados, una bolsa plástica transparente y tijera, moluscos agujereados, semillas, pallares y frijoles agujereados.

\subsection{TÉCNICAS}

Se empela la técnica de la torsión y el trenzado para elaborar el collar. 


\subsection{PROCEDIMIENTOS}

\section{INICIO}

Se muestra imágenes y réplicas de collares del Precerámico y se explica la función que tenían en la vida de los primeros grupos humanos.

La fibra vegetal a trabajar es el maguey, una planta de hojas en roseta, gruesas y carnosas, dispuestas sobre un tallo corto cuya piña inferior no sobresale de la tierra. Es muy común en América y se extiende, con 1200 especies, desde California en EEUU hasta el norte de Argentina. Su uso se remonta desde que el hombre llega al continente americano. (Fig. 10).

\section{PROCESO}

PRIMERO: Se procesa la planta extrayendo sus fibras, para ello una de sus hojas es machada con una roca, teniendo el cuidado de que no entrar en contacto la piel o los ojos con las sustancias líquidas que contiene el interior de las hojas puesto que son muy irritativas, luego del machacado se lava la planta con abundante agua para luego extraer sin problemas las fibras y dejar secar hasta que obtengan un color muy blanco (Fig. 11).

SEGUNDO: Las fibras secas se juntan formando tres grupos de 10 hebras cada uno y de un tamaño de $70 \mathrm{~cm}$ a $80 \mathrm{~cm}$. Se enrosca por el sistema de torsión obteniendo un conjunto de fibras enroscadas en forma de ocho, esto servirá para la soga del collar. (Fig. 12).

TERCERO: Se procede a agujerear los moluscos o semillas con la ayuda de un clavo de cemento, lentamente se va horadando, luego se inserta la soguilla y tenemos listo el collar.

- EVALUACIÓN: Se evalúa el proceso y el producto final, mostrando el empleo y conocimiento de la técnica y la creatividad al momento de elaborarlos (Fig. 13).

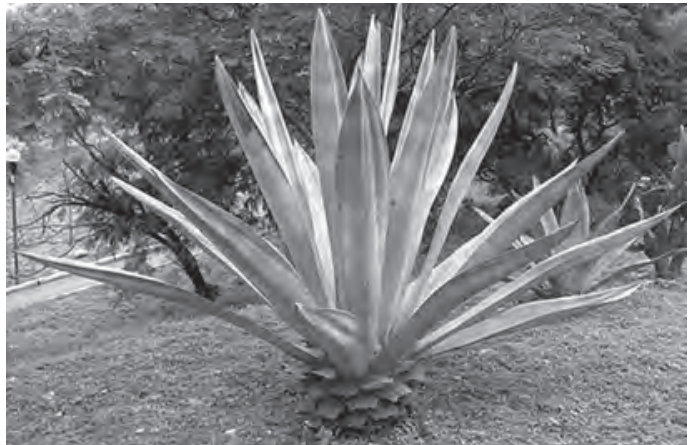

Figura 10

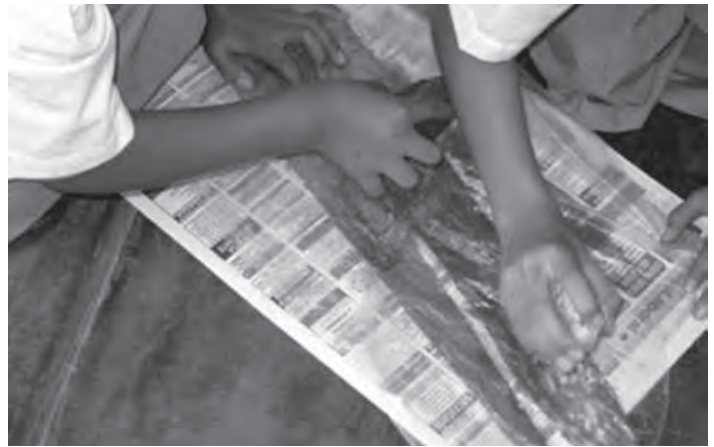

Figura 11

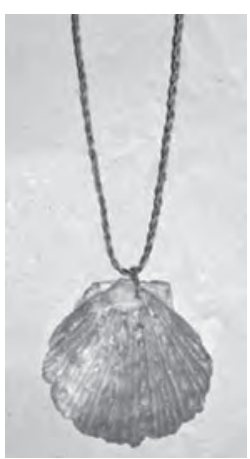

Figura 12

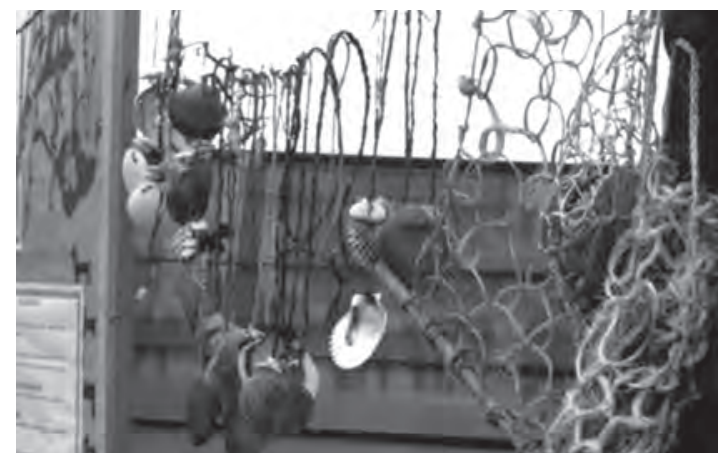

Figura 13 


\section{Taller 5: Fibras vegetales (elaboración de Redes de Pesca del PRECERÁMico)}

\subsection{DESCRIPCIÓN}

La pesca es, sin lugar a dudas, una de las primeras actividades del hombre encaminada a satisfacer sus necesidades alimentarias. A lo largo del tiempo y al igual que ocurrió con otras actividades de primera necesidad, la pesca se volvió una forma muy importante de sobrevivencia.

En un principio la pesca se limitaba a una simple recolección, que durante la bajamar recolectaba cangrejos, pequeños peces y moluscos que encontraba al descubierto. Esta práctica posteriormente fue reemplazada con la aparición del anzuelo que permitió la pesca de una mayor variedad de especies marinas, aunque con el aumento de la población humana que se acantonaba muy cerca al mar para aprovechar los alimentos que esta les brinda, aparecía la necesidad de obtener los alimentos del mar de manera masiva. El ingenio humano, ante tamaña necesidad, conllevó a solucionar el problema aprovechando su conocimiento en la utilización de las fibras vegetales que por seguro ya los conocía al momento de usarlo para la elaboración de sus vestidos y collares, con el empleo de esas técnicas elaboró por medio de telares muy elementales redes de pesca utilizando técnicas como los encontrados en Caral (Lima), Ancón (Lima), Chilca (Lima), Huaca Prieta (La Libertad), Santo Domingo (Ica), etc. Esas técnicas fueron el anudado, el entrelazado y el anillado.

5.2. OBJETIVO: Elaborar redes de pesca del Precerámico de forma creativa empleando antiguas técnicas y con la materia prima utilizada por antiguos pescadores.

\subsection{TIEMPO DE DURACIÓN: 90 minutos.}

\subsection{MATERIALES}

- Una hoja o penca de maguey (tamaño grande).

- Periódicos pasados.

- Moluscos agujereados (Conchas para collares).

- Una roca percutor para machacar la hoja de maguey.

- Palito de chupete o un palito de anticucho con punta recortada.

- Tijera.

\subsection{TÉCNICAS}

- El ANUDADO: Consiste en cruzar las soguillas de fibra vegetal formando nudos y dejando espacios en semicírculos, los amarrados deben de ir en orden de izquierda a derecha en horizontal, al llegar al extremo deben ser amarrados y luego volver a empezar desde el lado derecho al lado izquierdo formando una nueva secuencia horizontal, la operación se repite hasta llegar al final de las soguillas laterales que sirven como cuadrantes.

- EL ANILLADO: Consiste en cruzar las soguillas de fibra vegetal formando anillos dejando espacios en semicírculos, estos anillos al contrario de los nudos se pueden mover y resultan más flexibles o entendibles al momento de cumplir su función, su forma es como el de una «e» debajo de los semicírculos; los amarrados deben de ir en orden de izquierda a derecha en horizontal, al llegar al extremo deben terminar, ser recortados, amarrados y luego volver a empezar desde el lado derecho al lado izquierdo formando una nueva secuencia horizontal, la operación se repite hasta llegar al final de las soguillas laterales que sirven como cuadrantes. 
- EL TRENZADO: Consiste en cruzar las soguillas de fibra vegetal de forma vertical y horizontal, para ello primero se deben sujetar soguillas amarradas desde el palito superior del telar de forma que cuelguen de manera vertical; luego se cruzan tiras de soguilla de forma horizontal (Trama y urdimbre) estas deben cruzar sujetándose de manera ordenada a las fibras verticales de forma trenzada a manera de «8».

Los trenzados deben de ir en orden de izquierda a derecha en horizontal, al llegar al extremo deben terminar, ser recortados, amarrados y luego volver a empezar desde el lado derecho al lado izquierdo formando una nueva secuencia horizontal, la operación se repite hasta llegar al final de las soguillas laterales que sirven como cuadrantes.

\subsection{PROCEDIMIENTOS}

\section{INICIO}

Se muestra imágenes y réplicas de antiguas redes de pesca del Precerámico y se explica la función que tenían en la sobrevivencia de los primeros grupos humanos que habitaron en la costa.

\section{PROCESO}

PRIMERO: Se extrae las fibras del maguey, para ello se machacan sus hojas teniendo cuidado que las sustancias no esten en contacto con la piel o los ojos; luego de ello se lava la planta con abundante agua para luego extraer sin problemas las fibras y dejar secar hasta que obtengan un color muy blanco.

SEGUNDO: Las fibras secas se juntan formando varios grupos de 10 hebras cada uno, aproximadamente unos $40 \mathrm{~cm}$ de largo cada uno. Se enrosca por el sistema de torsión obteniendo un conjunto de fibras enroscadas en forma de ocho. La elaboración de la red de pesca del precerámico será de tamaño pequeño, la finalidad es aprender las técnicas e investigar los niveles de dificultad al momento de ser elaborados.

TERCERO: Con el empleo de un palito de chupete o palito de anticucho sin punta se elabora un rudimentario telar de mano, colocándolo de forma horizontal. Se inicia por la parte izquierda anudado a un extremo la soguilla, dejando suspendido al aire unos $20 \mathrm{~cm}$ de soguilla, luego desde la parte anudada al palito se empieza avanzar al lado derecho formando semicírculos y anudando se continua este procedimiento hasta llagar al extremo derecho del palito.

Si la soguilla al momento de ser anudado al palito esta se agota, deberá ser completada por otra soguilla para continuar con el tejido de la red. Al llegar al extremo izquierdo dejar suspendido también unos $20 \mathrm{~cm}$ de soguilla.

Continuar colocando niveles de tejido, este partirá del lado derecho al izquierdo y de acuerdo a la técnica elegida se irá avanzando hasta terminar la red de unos $20 \mathrm{~cm}$ de largo aproximadamente. (Fig. 14).

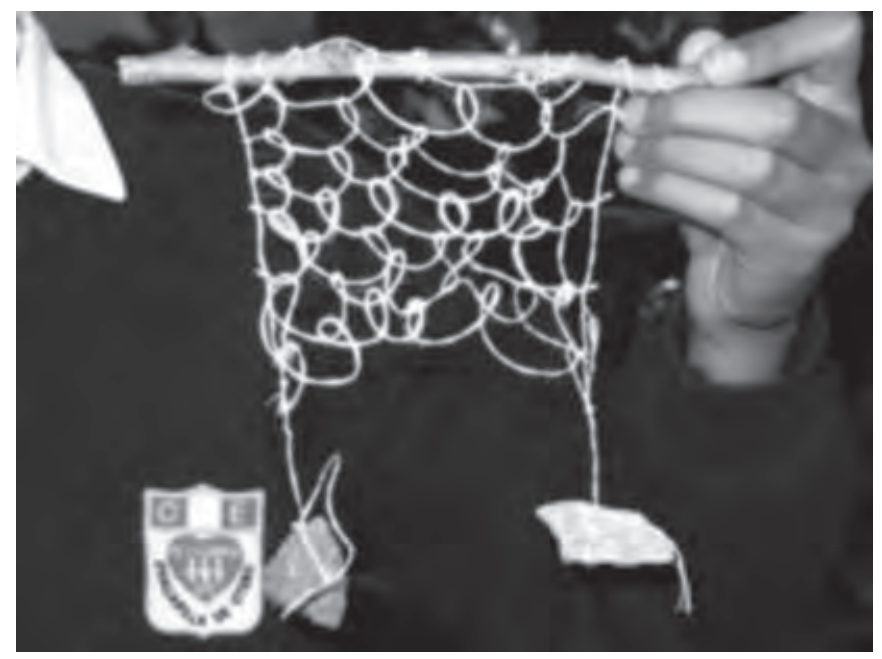




\section{TAller 6: Fibras Vegetales (ELABORAción DE SHicras)}

\subsection{DESCRIPCIÓN}

En la costa peruana durante el periodo precerámico no solo se hicieron redes; también se fabricaron canastillas y bolsas con fibras vegetales, útiles para conservar y cargar diversas cosas, semillas, frutos, caracoles y piedras. Una de estas útiles bolsas fueron las llamadas Shicras que es una especie de canastilla hecha a base de caña brava en la que los antiguos peruanos trasladaban hasta 20 kilos de piedras destinados como relleno constructivo.

Los habitantes de Caral - Supe, elaboraron shicras en junco y piedras para cimentar la construcción de pirámides obteniendo con ello una importante característica en su patrón arquitectónico. Shicra, en lengua quechua, significa bolsa que tiene una técnica de manufactura por anillado.

La técnica, se repite de manera idéntica desde el Precerámico en los Andes centrales y la Amazonía. Con los conocimientos obtenidos por parte de los estudiantes en la elaboración de redes de pesca del Precerámico, ellos están en la capacidad de poder elaborar shicras, puesto que su confección sigue las mismas técnicas de las redes solo que para ello se usan las soguillas vegetales del maguey en lugar del junco tal como se utilizaron en Caral.

\subsection{OBJETIVO}

Elaborar bolsas del precerámico (shicras) empleando antiguas técnicas y con la materia prima utilizada por antiguos habitantes de Caral.

\subsection{TIEMPO DE DURACIÓN}

90 minutos.

\subsection{MATERIALES}

- Una hoja o penca de maguey (tamaño grande).

- Periódicos pasados y tijera.

- Una roca percutor para machacar la hoja de maguey.

- Palito de chupete o un palito de anticucho con punta recortada.

- Piedritas y moluscos para el relleno de las shicras

\subsection{TÉCNICAS}

Las técnicas son las mismas del anudado y el anillado empleados en el taller de elaboración de redes de pesca del precerámico.

- El ANUDADO: Consiste en cruzar las soguillas de fibra vegetal formando nudos y dejando espacios en semicírculos, los amarrados deben de ir en orden de izquierda a derecha en horizontal, al llegar al extremo deben terminar, ser recortados, amarrados y luego volver a empezar desde la derecho formando una nueva secuencia horizontal, la operación se repite hasta llegar al final de las soguillas laterales que sirven como cuadrantes.

- EL ANILLADO: Consiste en cruzar las soguillas de fibra vegetal formando anillos dejando espacios en semicírculos, estos anillos al contrario de los nudos se pueden mover y resultan más flexibles o entendibles al momento de cumplir su función, su forma es como el de una «e» debajo de los semicírculos; los amarrados deben de ir en orden de izquierda a derecha en horizontal, al llegar al extremo deben terminar, ser recortados, amarrados y luego volver a empezar desde la derecho formando una nueva secuencia horizontal, la operación se repite hasta llegar al final de las soguillas laterales que sirven como cuadrantes. 


\subsection{PROCEDIMIENTOS}

- INICIO: Se inicia mostrando imágenes y réplicas de shicras del precerámico correspondientes a la cultura Caral y se explica la función que tenían en las construcciones arquitectónicas de templos de los habitantes de la costa central.

\section{- PROCESO}

Los procesos son los mismos del primero, segundo y tercero del empleado en el taller de elaboración de redes de pesca del precerámico.

PRIMERO: Se procede a procesar la planta el maguey extrayendo sus fibras, para ello una de sus hojas es machada con una roca, teniendo el cuidado de que no entrar en contacto la piel o los ojos con las sustancias líquidas que contiene el interior de las hojas puesto que son muy irritativas, luego del machacado se lava la planta con abundante agua para luego extraer sin problemas las fibras y dejar secar hasta que obtengan un color muy blanco.

SEGUNDO: Las fibras secas se juntan formando varios grupos de 10 hebras cada uno, aproximadamente unos cuarenta centímetros de largo cada uno. Se enrosca por el sistema de torsión obteniendo un conjunto de fibras enroscadas en forma de ocho. La elaboración de la red de pesca del precerámico será de tamaño pequeño, la finalidad es aprender las técnicas e investigar los niveles de dificultad al momento de ser elaborados.

TERCERO: Con el empleo de un palito de chupete o palito de anticucho sin punta se elabora un rudimentario telar de mano, colocándolo de forma horizontal. Se inicia por la parte derecha anudado a un extremo la soguilla, dejando suspendido al aire unos $20 \mathrm{~cm}$ de soguilla, luego desde la parte anudada al palito se empieza avanzar al lado derecho anudando al palito y dejando anillos colgados a manera de media luna.Si la soguilla al momento de ser anudado al palito esta se agota, deberá ser completada por otra soguilla para continuar con el tejido de la red. Al llegar al extremo izquierdo dejar suspendido también unos $20 \mathrm{~cm}$ de soguilla. Continuar colocando niveles de tejido, este partirá del lado derecho al izquierdo y de acuerdo a la técnica elegida se irá avanzando hasta terminar la red de unos $20 \mathrm{~cm}$. De largo aproximadamente.

CUARTO: Terminado la redecilla se procede a cerrarlo uniendo los extremos, para ello se dobla verticalmente por la mitad la redecilla uniendo los extremos de la parte superior e inferior. Luego los extremos derecho e izquierdo se anudan cerrándolo y formando una bolsita con la parte superior abierta. Para terminar se le agrega una soguilla en la parte superior para que sirva de lazo a la shicra.

- EVALUACIÓN: Se evalúa el proceso y el producto final, mostrando el empleo y conocimiento de la técnica y la creatividad al momento de elaborarlos (Fig. 15).

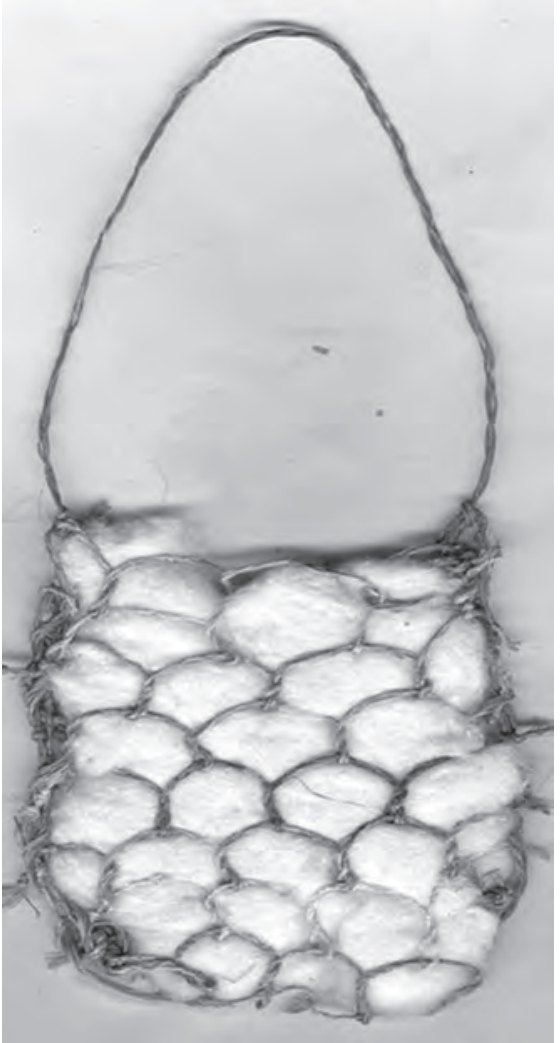




\section{TALLER 7: TeXTILERÍA PREHISPÁNICA}

\subsection{DESCRIPCIÓN}

Durante el periodo prehispánico la textilería constituyó una forma de expresión artística y sabemos que sus inicios se remontan a inicios del periodo precerámico, cuando se tejía con fibras vegetales como el junco y el maguey, su evolución se va dando con el posterior uso de la lana de camélidos y el algodón, para ello desarrollaron técnicas como el uso del telar que fue remplazando al tejido manual.

En la escuela se puede desarrollar la evolución de la textilería como un recurso didáctico de manera que los alumnos aprendan haciendo, a través del uso del maguey los estudiantes pueden iniciar el proceso de aparición de la textilería con la confección de redes de pesca usando técnicas del entrelazado, el anillado o el anudado, todas confeccionados manualmente, posteriormente estas redecillas de fibra vegetal pueden convertirse en útiles bolsitos que servirán para conservar y cargar diversos productos. Semillas, frutas, caracoles o piedras.

Su posterior evolución se puede plasmar con el uso del algodón o en su reemplazo ovillos de lana, pero para ello es necesario que los estudiantes cuenten con el uso de un telar de mano que ellos mismos pueden confeccionar, puesto que consiste en un simple marco de madera con clavos adheridos en los extremos superior e inferior, con la técnica de la trama y la urdimbre se pueden confeccionar pequeños lienzos multicolores que incluso pueden ser bordados con imágenes relacionados a tejidos de Huaca Prieta o Paracas.

\subsection{OBJETIVO}

Producir pequeños paños prehispanícos de forma creativa empleando antiguas técnicas y con la materia prima utilizada por antiguos habitantes del Perú.

\subsection{TIEMPO DE DURACIÓN}

90 minutos.

\subsection{MATERIALES}

- Un telar de mano (marco rectangular de 30 x $20 \mathrm{~cm}$ ) debe estar con pequeños clavos distribuidos en Zigzag separados un cm cada uno y clavados la punta sobre la parte superior e inferior del madero, esto servirá para poder sujetar la urdimbre y disponer sus hilos en forma paralela.

- Ovillos de lana de algodón de distintos colores.

- Dos espadas de madera o bastón de arrastre para formar las tramas $(30 \mathrm{~cm})$.

\subsection{TÉCNICAS}

Las técnicas empleadas son la trama sencilla y la urdimbre de hilos paralelos, constituidos por hilos que pasan por encima y por debajo de la urdimbre, siendo visible los hilos de los dos elementos. La superficie del tejido obtenida puede ser cerrada o abierta.

\subsection{PROCEDIMIENTOS}

\section{INICIO}

Se inicia mostrando imágenes y réplicas de textiles del precerámico, se explica la función, técnicas, materiales que usaron y la importancia de los textileros en el antiguo Perú. 


\section{PROCESO}

PRIMERO: Se tiene en cuenta los materiales a ser usados como el telar de mano, los ovillos de lana y las dos espada de madera que puede ser reemplazado por dos reglas de $30 \mathrm{~cm}$.

SEGUNDO: Se colocan las urdimbres de izquierda a derecha sujetándolos en los clavitos, los hilos o la lana van de forma paralela y en vertical, desde el extremo superior hasta el extremo inferior del telar rectangular de mano siempre la lana sujeto en los clavitos.

TERCERO: Ahora se pasará la trama que estaría sobre la urdimbre, se inicia desde la parte superior de las urdimbres. El textil a elaborarse es el llamado tejido plano o tela llana simple. Se cruzan los hilos de la trama por encima y por debajo de un hilo de urdimbre hasta llegar al otro extremo, Según se va avanzando y teniendo cierto grupo de tramas cruzadas se utiliza la espada de madera o palito de arrastre, este se utiliza para poder guiar al ejecutante en el tramado, la espada ayuda al levantamiento de las urdimbres pasando hacia atrás y hacia adelante sobre ellas en forma recta, luego se levanta y por debajo de ella se pasa el hilo de la trama, luego se baja la espada, se extrae y se vuelve a realizar la operación pasando varias veces el hilo de la trama con mucha más facilidad y rapidez (Fig. 16).

CUARTO: También puede ser cruce de dos hilos de la trama por encima y por debajo de un hilo de urdimbre. Otra práctica muy usada puede ser el tipo canasta que consiste en cruzar dos hilos por encima y por debajo de dos hilos de urdimbre. Los hilos de la trama deben ser combinados en grupos de varios colores al momento de ser cruzados por la urdimbre. Seguir este procedimiento hasta el final del telar (Fig. 17).

QUINTO: Terminado de elaborar la tela se extrae los anillos de la urdimbre que circundan los clavitos de arriba y abajo separando la tela totalmente del telar, los anillos son cortados quedando los hilos sueltos, estos luego son introducidos en los bordes de la tela con la ayuda de una aguja punta roma, los retacitos de hilo van saliendo en la tela y luego son cortados perdiéndose en la tela. Con esta última aplicación se termina el acabado de la tela.

\section{EVALUACIÓN}

Se evalúa el proceso y el producto final, mostrando el empleo y conocimiento de la técnica y la creatividad al momento de elaborarlos (Fig. 18).

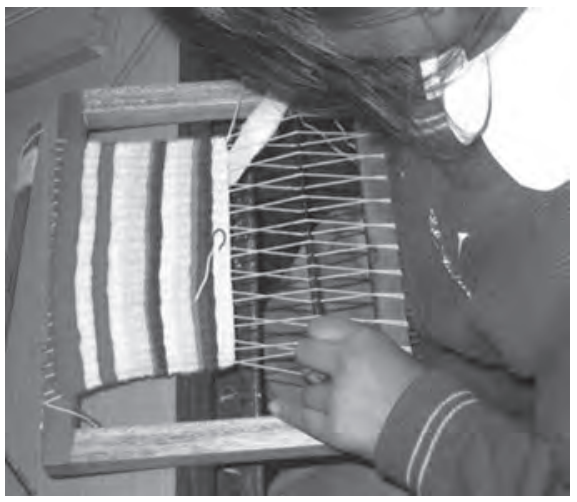

Figura 16

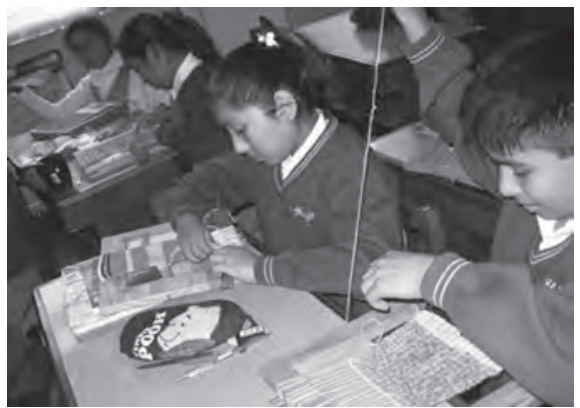

Figura 17

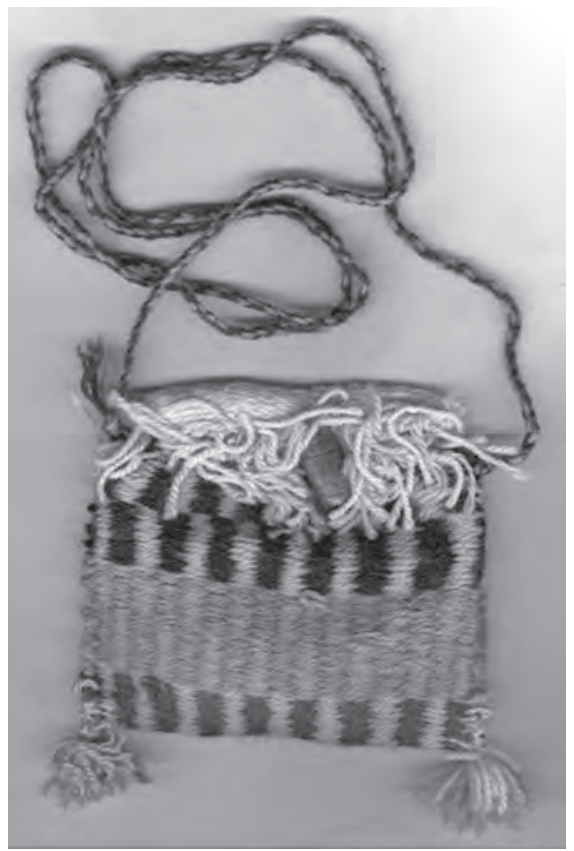

Figura 18 


\section{TALLER 8: Elaboración DE CERÁMicA PREHISPÁNicA}

\subsection{DESCRIPCIÓN}

Desde la aparición del hombre sobre la faz de la Tierra, la arcilla siempre estuvo presente y a su alcance por doquier, propiciando el origen de la alfarería tal vez con el conocimiento accidental de un trozo de arcilla cercano a un fogón o tal vez de una cesta de fibra vegetal recubierta de tierra arcillosa, hecho que asombraría al hombre al descubrir que el trozo u objeto hecho de tierra y agua se endurecía tornándose compacto e impermeable al ser alcanzado por el fuego.

Desde su descubrimiento, la cerámica se va a convertir en el mejor testimonio del hombre que lo va a acompañar des de su establecimiento en una vida sedentaria hasta nuestros días.

Los estudios de la cerámica y sus primeras apariciones se remontan al año 6000 a.C. en los pueblos agricultores y pastores que habitaron en el Asia Occidental. Hacia el año 3500 a. C. los Sumerios ya lo conocían y en el año 3000 a.C., también los japoneses. Las primeras evidencias en Sudamérica corresponde a sitios de Puerto Hormigas y Valdivia en Colombia y Ecuador respectivamente, su fechado se remonta al año 3100 a. C. En el caso del Perú su antigüedad se remonta entre el año 2000 a.C. al 1800 a.C. en la zona de Kotosh (Huánuco) y Ancón (Lima).

La idea con este taller es realizar un recorrido por los patrones evolutivos del surgimiento de la cerámica en el Perú desde sus inicios (2000 a. C.) con la aparición de los cuencos hasta llegar a ceramios más complejos del tipo Inca, utilizando técnicas sencillas y con patrones decorativos característicos.

\subsection{OBJETIVO}

Elaborar ceramios del precerámico para el desarrollo de la creatividad empleando antiguas técnicas y con la materia prima utilizada por antiguos habitantes del Perú.

\subsection{TIEMPO DE DURACIÓN}

90 minutos.

\subsection{MATERIALES}

Pizarra (plumones o tizas),fotocopias de separatas e imágenes, unos 2 kilos de arcilla preparada por cada estudiante, una esteca o cuchillo para trabajar en cerámica, un mandil, periódicos pasados.

\subsection{TÉCNICAS}

En el Perú prehispánico se conocieron dos maneras básicas de elaborar cerámica: mediante el modelado y el moldeado.

\subsection{PROCEDIMIENTOS}

\section{INICIO}

Se inicia mostrando imágenes y réplicas de cerámica prehispánica correspondientes a distintas culturas, se explica la función que tenían y las técnicas empleadas en su elaboración.

\section{PROCESO}

PRIMERO: Se verifica que todos los estudiantes tengan los materiales para la elaboración de su cerámica, se da instrucciones y recomendaciones para la elaboración.

SEGUNDO: El taller de cerámica se inicia con la técnica del Modelado, esta técnica consiste en dar forma con las manos a una vasija, se puede considerar los siguientes tipos: 
Modelado por presión manual: Partiendo de una bola de arcilla debidamente amasada y preparada se le hace un hueco en la parte central y se empieza a levantar y adelgazar gradualmente hacia arriba, hasta conseguir la forma deseada (Fig. 19).

Modelado por medio de rollos o salchichas: Consiste en ir superponiendo tiras o rollos de arcilla sobre una base circular, hasta obtener la forma y tamaño deseado, luego se borra las superficies internas y externas sobando sobre ellas con el uso de los dedos mientras permanezca húmeda (Fig. 20).

TERCERO: La segunda técnica empleada es el Moldeado, este trabajo es por medio de moldes con la finalidad de producir en serie, con fines comerciales o de intercambio. Para realizarlo primero se debe de obtener un positivo o modelar la vasija que se quiere reproducir, una vez lista se obtiene un negativo cubriendo con arcilla la forma original.

CUARTO: En esta parte se da el acabado final, consiste en darle el acabado superficial, una vez concluida la manufactura se procede a dejarla limpia y afinada, lista para su cocción, se puede usar las siguientes técnicas:

El alisado: Se frota la superficie con un canto rodado pequeño o un pedazo de tela, con ello se busca dejarla limpia, lisa y brillante.

El engobado: Consiste en un baño de la misma arcilla con el cual fue confeccionado la vasija e incluso se puede realizar con otro color de arcilla engobada como los realizado en Chancay con sus engobes en color crema.

\section{EVALUACIÓN}

Se evalúa el proceso y el producto final, mostrando el empleo y conocimiento de la técnica y la creatividad al momento de elaborarlos (Fig. 21).

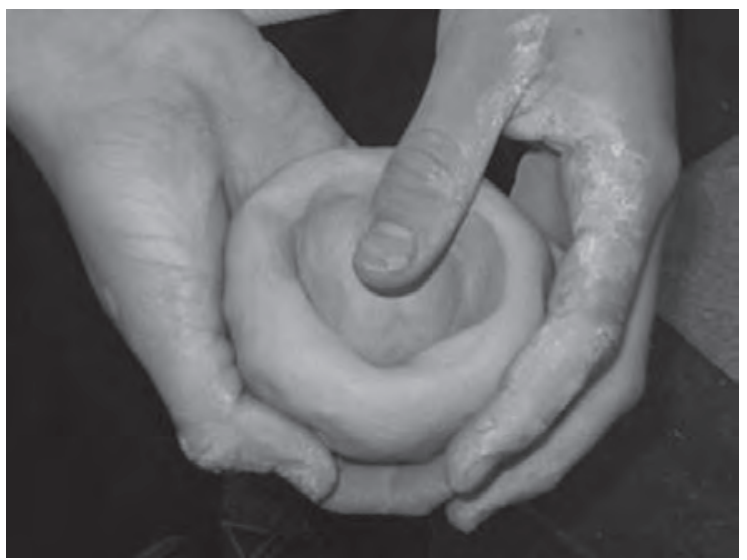

Figura 19

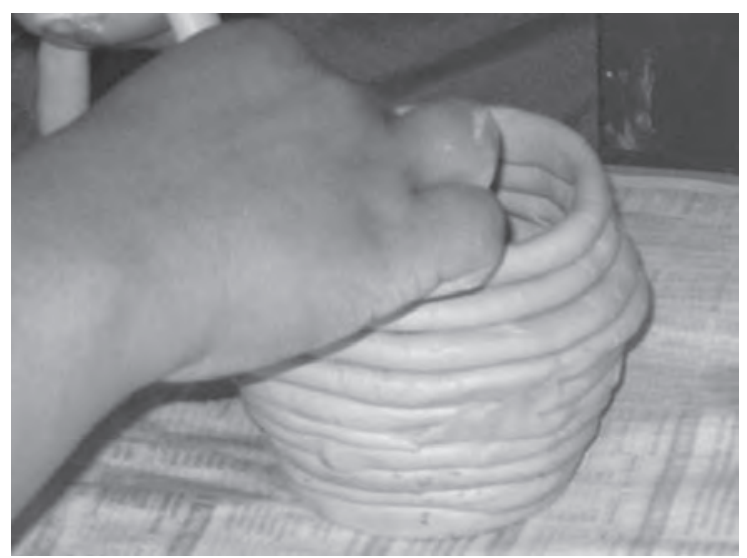

Figura 20

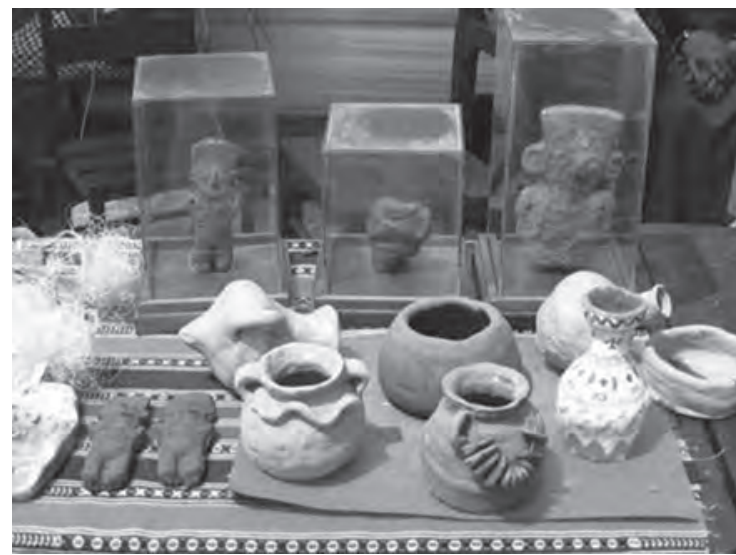

Figura 21 


\section{Agradecimientos}

Deseo expresar mi agradecimiento a insticiones como: Instituto Cultural Ruricancho, Colegio «Fe y Alegría №5»y Colegio «El Triunfo» y a los arqueólogos: Julio Abanto LLaque, Margarita Maysudo, Consuelo Gonzales y el Dr. Roger Ravines.

\section{BibliografíA}

\section{BEREZKIN, Yuri}

2000 «Archaeology and education in Postsoviet Russia». Antiquity. Rusia: Oxford, pag. 35.

DAVIS, Elain

2000 «Archaeology education and the political landscape of American schools». en Antiquity. EEUU: Oxford, pag. 47.

GINER, Vincent

2005 «Taller de Prehistoria» Revista Aula de Innovación Educativa. Barcelona - España. № 138: 90 - 96 . (en revista).

2005 «Taller de Romanos» Revista Aula de Innovación Educativa. Barcelona - España. № 139: 90 - 95. (en revista).

\section{GIMENO SACRISTAN, José}

1990 «Los Materiales y la Enseñanza» Cuadernos de Pedagogía. Chile. № 194 - 196. (en revista).

HENSON, Don

2001 «People and place. en History Today». EEUU. vol. 51, Pag. 12.

HOSTNIG, Rainer

2003 «Arte Rupestre del Perú - Inventario Nacional» Perú: CONCYTEC.

JIMÉNEZ, Carlos Alberto

2001 «El Taller Cotidiano y sus Aplicaciones». Colombia: KINESIS.

MANRIQUE, Elba

2001 «Guía Para un Estudio y Tratamiento de Cerámica Precolombina». Perú: CONCYTEC.

MARTÍNEZ, Diego

2002 «Manual de Arte Rupestre de Cundinamarca». Colombia: ICANH.

MINISTERIO DE EDUCACIÓN

2009 «Diseño Curricular Nacional de Educación Básica Regular». Perú: Ministerio de Educación. 2da edición.

PALOMINO, Oscar Emiliano

2010 «Orientaciones Para el Trabajo Pedagógico (OTP) del Área de Historia, Geografía y Economía». Lima Perú: Ministerio de Educación.

RAVINES, Rogger

1989 «Arqueología Práctica». Perú: LOS PINOS E.I.R.L

SILVESTRE, Margarita

2001 «Enseñanza y Aprendizaje Desarrollador». Cuba: COLECCIÓN PEDAGOGÍA CUBANA.

ZABALA, Antonio

2005 «Aprender desde los Museos». Revista Aula de Innovación Educativa. Barcelona - España. № 138: 23 26. (en revista). 